\title{
Phosphorylation of c-Jun in Avian and Mammalian Motoneurons In Vivo during Programmed Cell Death: An Early Reversible Event in the Apoptotic Cascade
}

\author{
Woong Sun, ${ }^{1}$ Thomas W. Gould, ${ }^{2}$ Jason Newbern, ${ }^{2}$ Carol Milligan, ${ }^{2}$ So Yoen Choi, ${ }^{1}$ Hyun Kim, ${ }^{1}$ and \\ Ronald W. Oppenheim ${ }^{2}$ \\ ${ }^{1}$ Department of Anatomy, College of Medicine, Brain Korea 21, Korea University, Sungbuk-Gu, Seoul, Korea 136-705, and 2Department of Neurobiology \\ and Anatomy and Neuroscience Program, Wake Forest University School of Medicine, Winston-Salem, North Carolina 27157
}

c-Jun is a transcription factor that is involved in various cellular events, including apoptotic cell death. For example, phosphorylation of c-Jun is one of the earliest biochemical changes detected in dying sympathetic neurons after NGF deprivation in vitro. However, currently, it is not known whether a similar molecular event is involved in the developmental programmed cell death (PCD) of neurons in vivo. We observed that only a subpopulation of motoneurons (MNs) exhibit c-Jun phosphorylation during the PCD period in chick [embryonic day 5 (E5)-E12] and mouse (E13-E18) embryos. Experimental perturbation of MN survival-promoting signals by limb bud removal (reduced signals) or by activity blockade (increased signals) in the chick embryo demonstrated that the presence of those signals is negatively correlated with the number of c-Jun-phosphorylated MNs. This suggests that insufficient survival signals (e.g., neurotrophic factors) may induce c-Jun phosphorylation of MNs in vivo. Consistent with the idea that c-Jun phosphorylation is a reversible event during normal PCD of MNs, we found that c-Jun phosphorylation was transiently observed in a subpopulation of mouse MNs rescued from PCD by deletion of the proapoptotic gene Bax. Inhibition of c-Jun signaling significantly reduced MN death in chick embryo, indicating that activation of c-Jun signaling is necessary for the PCD of MNs. Together, c-Jun phosphorylation appears to be required for the initiation of an early and reversible event in the intracellular PCD cascade in vivo after loss of survival-promoting signals such as neurotrophic factors.

Key words: motoneurons; cell death; target; c-Jun; phosphorylation; in vivo

\section{Introduction}

The development of the nervous system involves the elimination of excess neurons for sculpting proper functional connections between neurons and their targets (Oppenheim, 1991). In the chicken spinal cord, approximately one-half of all motoneurons (MNs) produced during neurogenesis undergo programmed cell death (PCD) after establishing provisional synaptic contacts with target muscles. Although the precise mechanisms involved are not completely understood, competition of $\mathrm{MNs}$ for limited availability of trophic signals from the target is thought to be critical for the developmental PCD of MNs (Oppenheim, 1991). Consistent with this notion is evidence showing that the removal or absence of target muscles greatly augments the PCD of MNs, whereas the addition of extra targets or treatment with exogenous target-derived neurotrophic factors attenuates PCD of MNs (Hamburger and Levi-Montalcini, 1949; Hamburger, 1975;

Received Dec. 6, 2004; revised April 28, 2005; accepted April 29, 2005.

This work was supported by National Institutes of Health Grants NS20402, NS048982 (R.W.0.), and NS036081 (C.M.), a grant from the Packard Amyotrophic Lateral Sclerosis Center of Johns Hopkins University (R.W.0.), and Korean Ministry of Science and Technology Grants M10412000078-04N1200-07810 and M103KV010018-03K220101820. We are especially grateful to Christopher Bonny for providing D-JIKI1.

Correspondence should be addressed to Dr. Woong Sun, Department of Anatomy, College of Medicine, Brain Korea 21, Korea University, 126-1 Anam-Dong, Sungbuk-Gu, Seoul, Korea 136-705.E-mail: woongsun@korea.ac.kr. DOI:10.1523/JNEUROSCI.4970-04.2005

Copyright $\odot 2005$ Society for Neuroscience $\quad$ 0270-6474/05/255595-09\$15.00/0
Phelan and Hollyday, 1991; Calderó et al., 1998; Grieshammer et al., 1998). Primarily because of their experimental accessibility, chicken MNs have been widely used as a model for developmental investigations of target-dependent PCD in vivo.

Because the purification and culture of large numbers of MNs for biochemical studies is relatively difficult, many in vitro studies have instead focused on peripheral sympathetic neurons and cerebellar granule cells (Deckwerth et al., 1996, 1998; Easton et al., 1997; Miller et al., 1997; Putcha et al., 1999, 2001). The survival of cultured sympathetic neurons is NGF dependent, and the removal of NGF from the culture media synchronously evokes apoptotic cell death, which provides an excellent model for examination of the cell death cascade in vitro (Chun and Patterson, 1977; Greene, 1977; Deckwerth et al., 1998). One of the earliest events after NGF deprivation in this model is the phosphorylation of c-Jun (Easton et al., 1997; Miller et al., 1997; Deckwerth et al., 1998; Putcha et al., 2001). Because c-Jun is a transcription factor that interacts with either other members of the c-Jun family or with c-Fos, the activation of c-Jun may induce downstream cell death-related gene expression. For instance, the expression of Bim, a member of the Bcl-2 homology domain 3 (BH3)-only family of proteins, is transcriptionally regulated by c-Jun, and the induction of Bim appears to be important for Bax translocation, which is critical for apoptotic neuronal death (Putcha et al., 2001). Inhibition of c-Jun activation, either by overexpression of 
dominant-negative c-Jun (DN-Jun) or by a pharmacological blockade of upstream kinases, greatly reduced the apoptosis of cultured sympathetic neurons in the absence of NGF (Putcha et al., 2001; Whitfield et al., 2001). These observations indicate that c-Jun participates in an early activation step of sympathetic neuronal death. However, it is not clear whether phosphorylation of c-Jun is also critical for other types of neurons or more importantly for neuronal death in vivo. For instance, the PCD of trigeminal ganglion neurons is apparently normal in c-Jun knockout (c-Jun-KO) mice (Herzog et al., 1999).

In this study, we examined the temporal changes in c-Jun phosphorylation and the effect of inhibition of c-Jun signaling in MNs during the PCD period in vivo. Our observations indicate that c-Jun phosphorylation is involved in an early and reversible activation step in MN death that appears to be triggered by an insufficient supply of survival signals.

\section{Materials and Methods}

Animals. Fertilized white leghorn chicken eggs were obtained from Hubbard Farms (Statesville, NC) and incubated at $37^{\circ} \mathrm{C}$ and $60 \%$ relative humidity. Their age was determined by reference to the HamburgerHamilton (HH) chick embryo stage (st.) series (Hamburger and Hamilton, 1951). The heterozygous Bax-KO mice were maintained on a C57BL/6 background and mated to generate homozygotes. Sibling animals at the indicated embryonic ages were collected and individually genotyped by PCR as described previously (Knudson et al., 1995).

Histology. Embryos were immersion fixed in 4\% paraformaldehyde and cryoprotected in $30 \%$ sucrose. For quantitative analysis, lumbar spinal cords were serially sectioned $(8 \mu \mathrm{m})$ on a cryostat, and every 10 th or 20 th section was analyzed. To retrogradely label a subpopulation of facial MNs, Alexa488-conjugated cholera toxin B subunits (Molecular Probes, Eugene, OR) were injected into the whisker pads of postnatal day 1 (P1) wild-type (WT) and Bax-KO mice, and the animals were killed after a $2 \mathrm{~d}$ survival (Sun et al., 2003). Animals were perfused with $4 \%$ paraformaldehyde and cryoprotected in 30\% sucrose, and brains were serially sectioned $(20 \mu \mathrm{m})$ on a cryostat. For immunostaining, sections were blocked with $10 \%$ normal goat serum and $0.1 \%$ Triton X-100 in PBS for $30 \mathrm{~min}$, followed by incubation with primary antibodies against phosphorylated c-Jun (P-Jun) II (1:200; Ser63; Cell Signaling Technology, Beverly, MA), sc-45 (1:200; Santa Cruz Biotechnology, Santa Cruz, CA), anti-activated caspase-3 (1:200; Cell Signaling Technology), phosphoAkt (p-Akt; 1:500; Cell Signaling Technology), Islet1/2 (1:200; Developmental Hybridoma Bank, Iowa City, IA), Lim2 (1:200; Developmental Hybridoma Bank), Hoxc10 (1:200; Developmental Hybridoma Bank), and unphosphorylated neurofilaments (1:1000; SMI-32; Sternberger Monoclonals, Lutherville, MD) overnight at $4^{\circ} \mathrm{C}$. After several washes in PBS, a mixture of Alexa488-conjugated goat anti-mouse IgG (1:500; Molecular Probes), cyanine 3-conjugated goat anti-rabbit IgG (1:500; Vector Laboratories, Burlingame, CA), and Hoechst 33342 (10 $\mu \mathrm{g} / \mathrm{ml}$; Sigma, St. Louis, MO) was applied for $30 \mathrm{~min}$. Sections were then washed, mounted, and observed under an epifluorescence microscope. Images were digitized by CCD camera and optimized with Photoshop 5.0 (Adobe Systems, San Jose, CA). Although very weak P-Jun immunoreactivity (IR) in the peri-nucleolar region within the nucleus was observed in most chick spinal neurons, we considered this to be nonspecific background and excluded those cells from additional examination (see Results).

Limb bud removal. Unilateral removal of the limb bud in the chick embryo was performed on embryonic day 2.5 (E2.5) (HH stage 16-18) using surgical methods described previously (Calderó et al., 1998). Because this is before $\mathrm{MN}$ axons have innervated the limb, axotomy was ruled out as contributing to later cell death. Only those embryos later found to have a complete loss of the leg and pelvic girdle were used for additional analysis. Because unilateral limb bud removal (LBR) in the chick does not alter the development of contralateral MNs, the contralateral side was used as a control.

Activity blockade. For the treatment of embryos with activity-blocking agents, a window was made in the shell over the embryo on E3 (st. 20), and $\alpha$-bungarotoxin $(\alpha$-BTX; $100 \mu \mathrm{g})$ or saline was applied once daily onto the highly vascularized chorioallantoic membrane beginning at E5 (st. 26). Complete blockade of activity was verified by the absence of spontaneous movement of embryos that were monitored for a $5 \mathrm{~min}$ period (blindly), $6 \mathrm{~h}$ after each daily treatment (Oppenheim et al., 2000).

In ovo electroporation. DN-Jun was prepared by PCR amplification of mouse c-Jun with truncation of the $\mathrm{C}$ terminal from amino acid 169 $(\Delta 169)$, which has been successfully used for c-Jun signaling blockade (Whitfield et al., 2001). The c-Jun $\Delta 169$ fragment was then inserted into the pYFP-C1 vector (Clontech, Cambridge, UK). Sequence was verified to check for mutations, and the production of full-length protein was also examined by Western blot analyses (data not shown). For electroporation, chick embryos were incubated until stage 15, windowed, and bathed in a small amount of sterile PBS. The electrodes were placed on the left and right sides of the embryo. Plasmid DNA $(2 \mu \mathrm{g} / \mu \mathrm{l})$ containing $1 \times$ DNA loading buffer (Promega, Madison, WI) was injected in the lumen of the neural tube. Five $25 \mathrm{~V}$ pulses, $50 \mathrm{~ms}$ each with a $950 \mathrm{~ms}$ interval, were applied. Egg windows were then covered and sealed, and the eggs were reincubated. Although we used the cytomegalovirus promoter, yellow fluorescent protein (YFP) signals were predominantly observed in the ventral horn at E7. However, there was no such selective localization of the YFP signal when examined at E5, suggesting that the expression of YFPtagged protein is reduced in spinal interneurons between E5 and E7. We reasoned that the proliferation of interneuron precursors (Hollyday and Hamburger, 1977) during this period may eliminate the electroporated plasmids, and therefore YFP signal gradually disappeared.

Ex vivo treatment with a $\mathrm{c}$-Jun $\mathrm{N}$-terminal protein kinase inhibitor. On E7.5, chick embryos were killed and eviscerated, and a ventral laminectomy performed in oxygenated Tyrode's solution. One hindlimb was injected with either saline or $5 \mathrm{~mm} \mathrm{D-JIKI1,} \mathrm{together} \mathrm{with} \mathrm{the} \mathrm{retrograde}$ tracer Alexa-Fluor 594-conjugated cholera toxin, to visualize lumbar MNs affected by drug treatment. Control limbs were only injected with the retrograde tracer. D-JIKI1 is a cell-permeable, protease-resistant peptide that blocks the access of c-Jun N-terminal protein kinase (JNK) to many of its targets (Bonny et al., 2001; Borsello et al., 2003a,b). Treatment in ovo with doses of D-JIKI1 sufficient to inhibit phosphorylation of c-Jun were embryonic lethal (data not shown). Spinal cord-hindlimb preparations were incubated at $32^{\circ} \mathrm{C}$ for $16 \mathrm{~h}$ in $1 \mathrm{~L}$ of oxygenated Tyrode's solution (medium changed once after $8 \mathrm{~h}$ ). After incubation, spinal columns were fixed for $1 \mathrm{~h}$ with $4 \%$ paraformaldehyde, transferred to $30 \%$ sucrose, and embedded in three parts $30 \%$ sucrose to two parts OCT cryopreservation compound; next, $10-\mu \mathrm{m}$-thick sections were cut on a cryostat at $-30^{\circ} \mathrm{C}$ and stained with Hoechst 33342 . Labeled pyknotic nuclei in $\mathrm{MNs}$ that were retrogradely labeled were counted blind in every 10th section of the entire lumbar lateral motor column (LMC) (Gould and Oppenheim, 2004). Cultured lumbar chick embryo MNs were used to demonstrate that D-JIKI1 inhibits c-Jun phosphorylation. Lumbar spinal cords from E5 embryos were dissected and dissociated, and MNs were purified by centrifugation in a metrizimide gradient. Purified MNs were plated in laminin-coated 24 -well plates for $8 \mathrm{~h}$ in serum-free medium in the presence of muscle extract and $3 \mu \mathrm{M}$ D-JIKI1, as described previously (Milligan et al., 1994). D-JIKI1 and whole-protein lysates were collected and analyzed by Western blotting.

\section{Results}

Developmental changes in c-Jun phosphorylation in the chick In E7 (st. 33) chicken spinal cord, only a subset of motor, dorsal root ganglion (DRG), and superior cervical ganglion (SCG) neurons exhibited positive immunolabeling for phosphorylated c-Jun (Fig. 1). Double-immunofluorescence labeling for P-Jun (green) and Islet1/2 (a specific marker for MNs as well as a subset of peripheral sensory and sympathetic neurons; red) demonstrated that a subpopulation of Islet $1 / 2+$ MNs in the LMC was P-Jun +. Similarly, only a subset of Islet $1 / 2+$ DRG and sympathetic neurons exhibited c-Jun phosphorylation at E7. In contrast, chicken spinal interneurons, which do not undergo developmental PCD (McKay and Oppenheim, 1991), never exhibited 

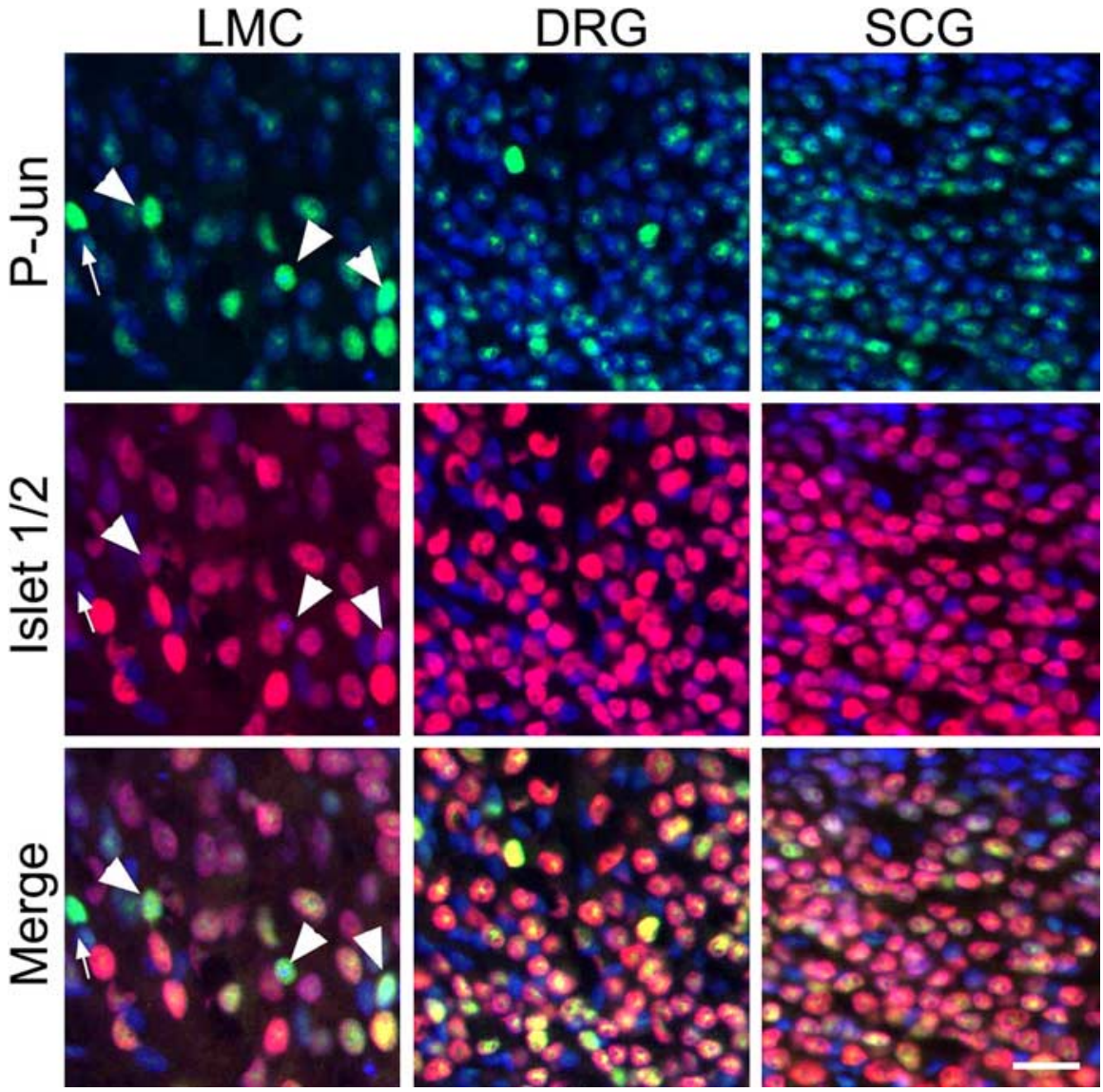

Figure 1. Phosphorylation of c-Jun (green; top) in a subset of MNs, DRG neurons, and SCG neurons in an E7 chick embryo. Islet $1 / 2$ was used (red; middle) to identify motor, sensory, and sympathetic neurons. Nuclei were counterstained with Hoechst 33342 (blue). Many P-Jun + MNs exhibited only very weak (yellowish green; arrowheads) or no (green; arrow) Islet1/2 staining, as shown in the merged images (bottom). Scale bar, $40 \mu \mathrm{m}$.

phosphorylation of c-Jun (data not shown) (but see Fig. 2). Interestingly, many P-Jun + MNs exhibited only weak (Fig. 1, arrowheads, yellowish green in merged image) or no (Fig. 1, arrows, green in merged image) Islet $1 / 2$ IR, although they were all within the LMC (Fig. 1), suggesting that Islet $1 / 2$ expression may be downregulated in this subpopulation of P-Jun + MNs. Downregulation of $\mathrm{MN}$-specific marker expression during the $\mathrm{PCD}$ period appears to be common, because the expressions of other MN markers such as Lim2 and Hoxc10 were also reduced in a subpopulation of P-Jun+ MNs (see supplemental material, available at www.jneurosci.org).

Next, we quantified the number of P-Jun + MNs during the entire PCD period (Fig. 2). P-Jun + MNs were present at E5 (st. 26), peaked on E8 (st. 34), and were subsequently reduced in number. However, at E12-E14 (st. 38-40), when the developmental PCD of MNs is complete (Hamburger, 1975), 10\% of MNs were still P-Jun +, whereas by E16 (st. 42), P-Jun + neurons were no longer present. Using adjacent sections, we also assessed the number of apoptotic cells present at each age. To identify apoptotic cells, we used sc- 45 immunostaining, which recognizes a cleaved product of activated caspase- 3 that is present in virtually all chick neurons undergoing PCD and which is correlated quantitatively with terminal deoxynucleotidyl transferase-mediated biotinylated UTP nick end labeling-positive and pyknotic MNs (Calderó et al., 1998; Ayala et al., 1999; Cascas et al., 2001; Sato et al., 2002). Sc-45+ cells were first observed on E6, peaked at E8, then sharply declined and disappeared by E14.
At least three major differences were observed in sc-45-immunoreactive versus P-Jun-immunoreactive cells during the PCD period (Fig. 2): (1) sc-45+ cells were first observed on E6, whereas P-Jun + cells first appeared on E5, indicating that phosphorylation of c-Jun occurs earlier than the activation of caspase-3; (2) the number of P-Jun + cells was $\sim 10$-fold higher than that of sc-45+ cells during the major period of PCD, E6-E10; and (3) sc-45+ $\mathrm{MNs}$ had disappeared by the end of the PCD period, whereas P-Jun+ MNs were present until E14.

\section{Phosphorylation of c-Jun after experimental perturbation of PCD}

Next, we examined whether experimental alteration of the extent of MN PCD affects the number of P-Jun + cells. LBR at HH st. 16-18 before motor axons innervate limb targets greatly augments the later PCD of MNs (Calderó et al., 1998). Between E5 and E10 (st. 26-36), when large numbers of MNs degenerate on the LBR side of the spinal cord versus the contralateral (control) side, the ipsilateral LMC was greatly reduced in size, and significantly more ipsilateral MNs were P-Jun+ (Fig. 3).

In contrast, the experimental reduction of MN PCD by activity blockade greatly reduced the number of P-Jun + cells (Fig. 4). Blockade of neuromuscular activity during the PCD period rescues most MNs from death (Pittman and Oppenheim, 1979; Oppenheim et al., 2000), and this rescue effect appears to be closely related to an increase in the intramuscular branching of MN axons, which may increase the access of these MNs to target-derived trophic signals (Oppenheim, 1989; Landmesser, 1992). After treatment with $\alpha$-BTX from E5 to E7 (st. 26-33), the number of P-Jun + cells was diminished to $20 \%$ of control values on E8 (st. 34), and, as expected, there was a marked increase in the number of healthy surviving MNs $(13,420 \pm 897, n=3$ vs $20,060 \pm 1942, n=3 ; p<$ $0.01 ; t$ test).

After the cessation of daily treatment with $\alpha$-BTX from E5 to E9 (st. 26-35), MNs underwent a delayed period of PCD (Fig. $4 C$ ). There were $\sim 60 \%$ more MNs at E10 (st. 36) compared with saline control (11,040 vs 17,660$)$, and this difference was maintained until E12 (saline, 11,900 vs $\alpha$-BTX, 18,500). However, after E12, the number of surviving MNs in the experimental group decreased such that by E16, MN numbers were similar in the two groups (9500 vs 9640). Thus, by E12, as neuromuscular activity and embryonic movements resume (Pittman et al., 1978; Pittman and Oppenheim, 1979), a delayed PCD of the rescued MNs occurs. Surprisingly, on E12 (st. 38), 70\% of MNs were still P-Jun + after $\alpha$-BTX treatment from E5 to E9, although $<50 \%$ of these E12 MNs will subsequently undergo delayed cell death between E12 and E16 (Fig. 4).

Phosphorylation of Akt in a subpopulation of P-Jun+ MNs Because we observed that there are significantly more P-Jun+ MNs compared with the number of apoptotic cells, we reasoned 
that phosphorylation of c-Jun is necessary but not sufficient for $\mathrm{MN}$ death and that interaction with other survival-related pathways may influence whether MNs undergo PCD. One candidate for an alternative survival signaling pathway is phosphatidylinositol 3-kinase (PI3K)-Akt-Bad (Kaplan and Miller, 2000; Brunet et al., 2001). Consistent with this possibility, double-immunofluorescence labeling for P-Akt and P-Jun demonstrated that $\sim 50 \%$ of P-Jun + MNs lost P-Akt IR (Fig. 5 ). These data suggest that the induction of stress-induced signaling (P-Jun) in combination with the loss of trophic factor signaling (loss of P-Akt) may regulate the fate of MNs by a competitive process during normal PCD.

Increased c-Jun phosphorylation in the Bax-KO mouse

Recently, it has been shown that the PCD of many populations of postmitotic neurons is mediated by the proapoptotic gene Bax (Deckwerth et al., 1996; White et al., 1998; Sun et al., 2003). For instance, sympathetic neurons from Bax-KO mice live indefinitely without NGF in vitro (Deckwerth et al., 1996). Similarly, Bax-KO MNs are rescued from death during normal development or after neonatal axotomy (Deckwerth et al., 1996; White et al., 1998; Sun and Oppenheim, 2003; Sun et al., 2003). However, although Bax rescues developing MNs from PCD, the rescued cells become atrophic and fail to maintain innervation of targets (Sun et al., 2003). Therefore, it was of considerable interest to examine the pattern of c-Jun phosphorylation of MNs in Bax-KO mice (Fig. 6).

In WT mice, similar to our observations in the normal chick embryo (Fig. 1), P-Jun + cells were restricted to a subset of ventral horn MNs on E15 during the PCD period (Fig. 5). In contrast to WT mice and to the normal chick embryo, however, most lumbar MNs in Bax-KO mice exhibited c-Jun phosphorylation at E15, similar to the situation of delayed PCD after transient activity blockade in the chick embryo (compare Figs. 4 and 6). The number of $\mathrm{P}-J u n+$ neurons in the Bax-KO remained high until P0. Although most P-Jun+ MNs in WT mice also expressed the MNspecific marker SMI-32 (Fig. 6, arrows and insets), many P-Jun $+\mathrm{MNs}$ in Bax-KO mice failed to exhibit SMI-32 IR (Fig. 5, arrowheads and insets). Quantification of SMI-32+ cells in the P-Jun + population revealed that their numbers were similar in P0 WT and Bax-KO mice, whereas the number of P-Jun+/SMI-32- neurons was dramatically increased in Bax-KO
A E6
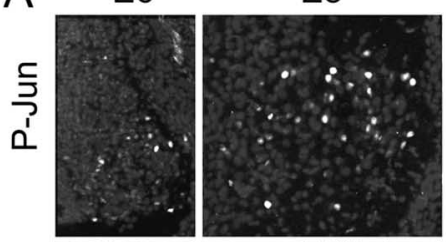

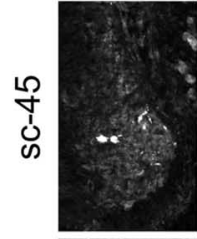

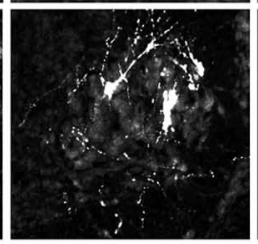

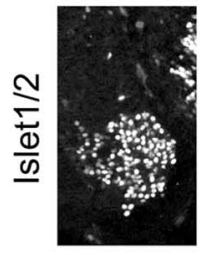

B

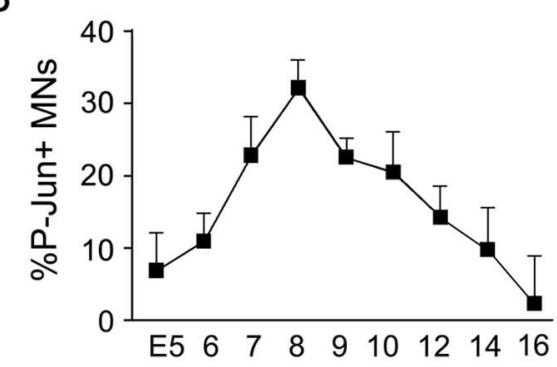

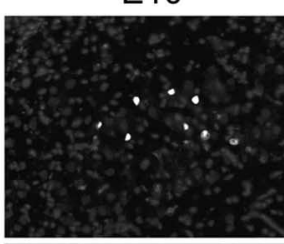

E10
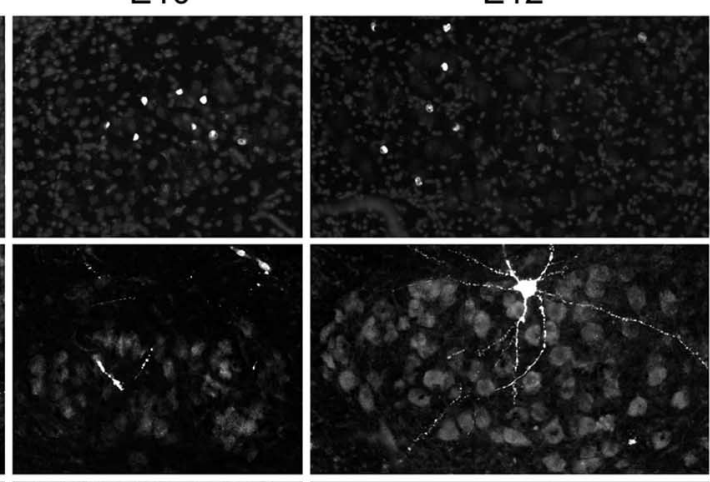

E12
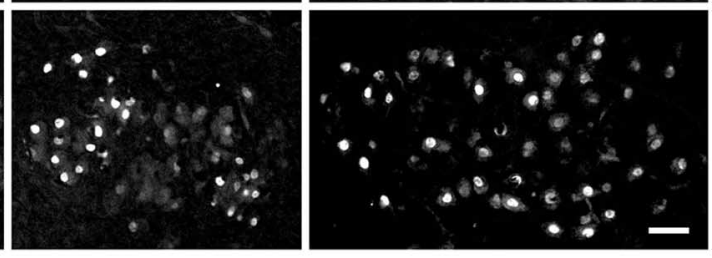

C

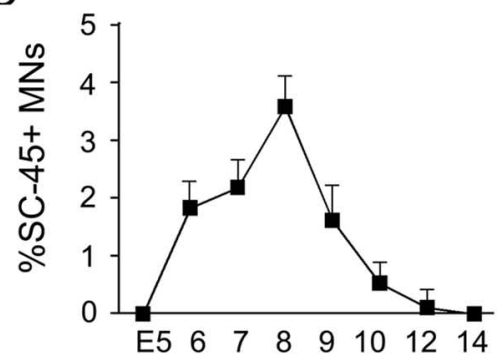

Figure 2. A, Developmental changes in the number of $\mathrm{P}$-Jun + MNs. In adjacent sections, the apoptotic marker protein (sc-45; middle) and Islet1/2 (bottom) expression are shown. Note that interneurons located outside of the lateral motor column never exhibit P-Jun IR. Scale bar, $60 \mu \mathrm{m}$. B, Quantification of P-Jun + MNs in the lumbar spinal cord of the developing chicken embryo during the PCD period. C, Quantification of sc-45+ MNs during the PCD period (mean $\pm S D ; n=3$ per age in $\boldsymbol{B}$ and $C$ ).

A

ณ

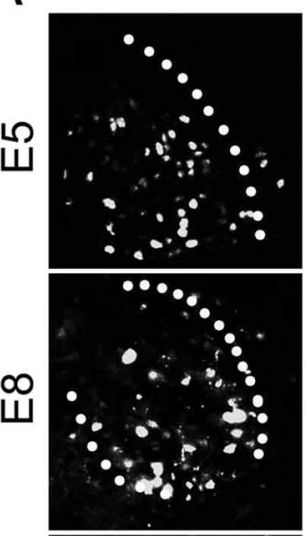

LBR

CON
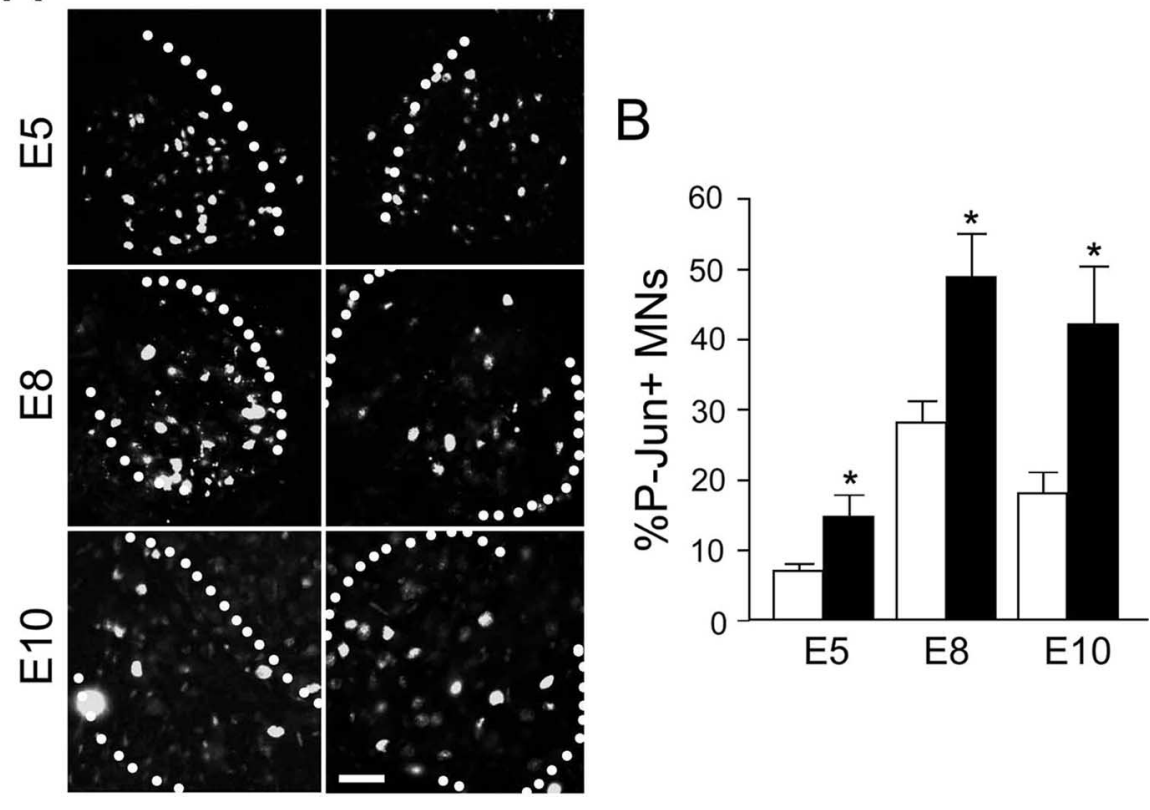

Figure 3. A, Phosphorylation of $\mathrm{C}-\mathrm{Jun}$ in MNs on the ipsilateral LBR versus contralateral (CON) side of the lumbar spinal cord. The dotted line indicates the border of the lateral motor column in the lumbar spinal cord at E5, E8, and E10. Scale bar, $60 \mu \mathrm{m} . \boldsymbol{B}$, Quantification of P-Jun + MNs after unilateral LBR. Open bars, Contralateral; black bars, ipsilateral. Data are mean values \pm SD obtained from nine lumbar spinal cord sections from three different animals. ${ }^{*} p<0.05 ; t$ tests. 

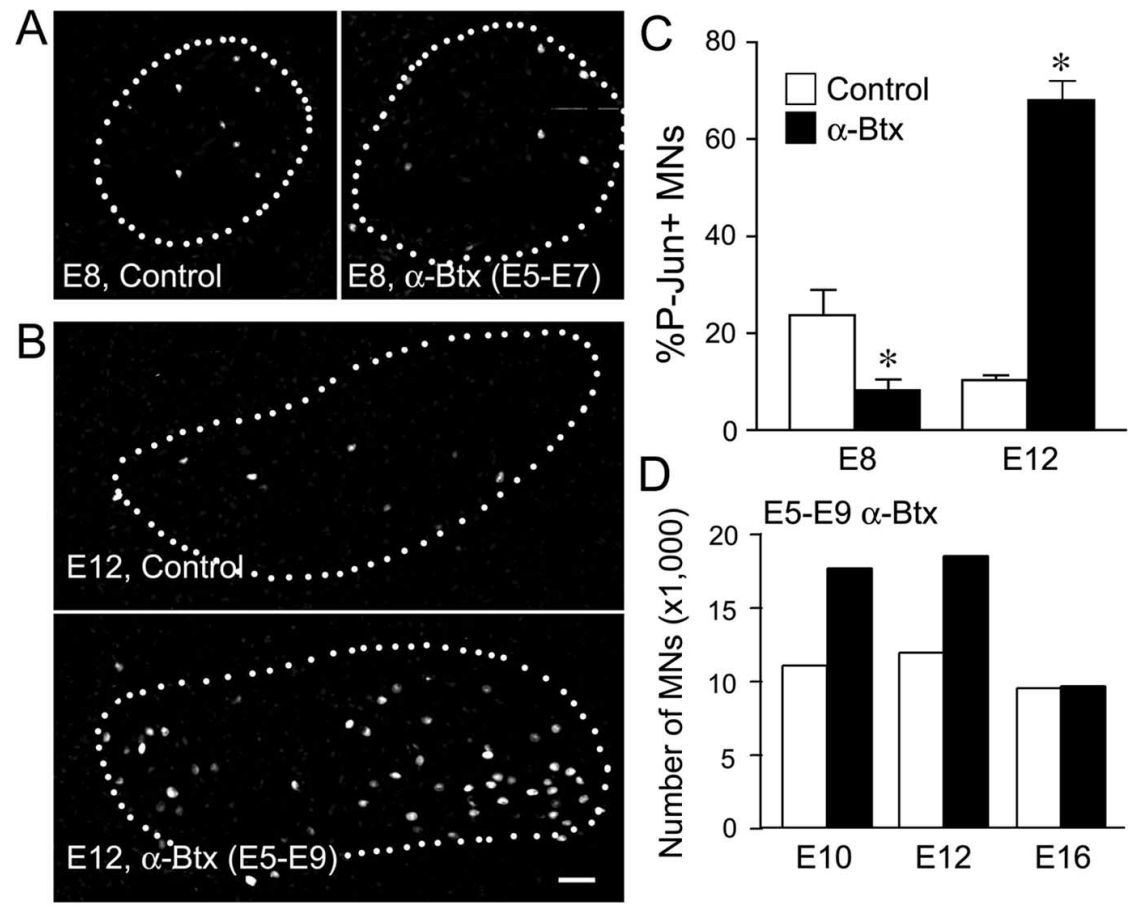

Figure 4. Phosphorylation of c-Jun in MNs after activity blockade. The dotted line encloses the lateral motor column in the lumbar spinal cord. $A$, Reduction of P-Jun + MNs in the E8 spinal cord after E5-E7 activity blockade by $\alpha$-BTX treatment. Note that the LMC in the $\alpha$-BTX-treated embryo is larger than in the control because of the inhibition of developmental PCD. Scale bar, 60 $\mu \mathrm{m} . \boldsymbol{B}$, Induction of P-Jun + MNs in the E12 spinal cord after E5-E9 $\alpha$-BTX treatment. $\boldsymbol{C}$, Data are mean values \pm SD obtained from nine lumbar spinal cord sections from three different animals. ${ }^{*} p<0.05$. D, The number of surviving MNs after E5-E9 activity blockade. To determine the changes in healthy surviving MN numbers, NissI+ neurons were counted in two embryos at each time point. The number of MNs remained high in activity-blocked embryos on E12 but was reduced to control values by E16. These data are consistent with data from more extensive analyses in several previous studies (Pittman et al., 1978; Pittman and Oppenheim, 1979; Oppenheim et al., 2000).

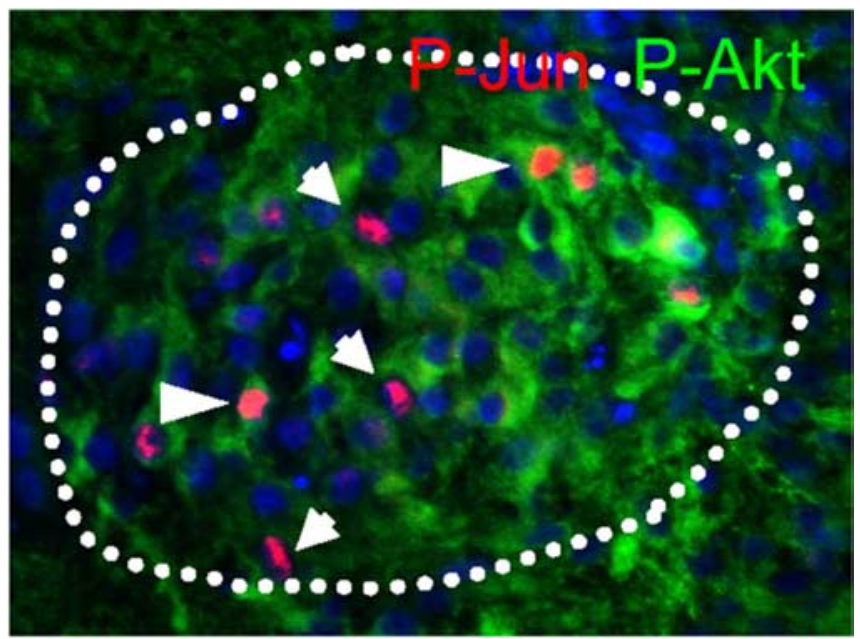

Figure 5. Phosphorylation of Akt in a subpopulation of P-Jun + MNs. Doubleimmunofluorescence staining of P-Jun (red) and P-Akt (green) was performed on E7 chick spinal cord. The dotted line indicates the lateral motor column in the lumbar spinal cord. Note that a subset of P-Jun + MNs exhibits P-Akt IR (arrowheads), whereas the remaining subset of P-Jun + MNs is P-Akt negative (arrows).

mice (Fig. 6C). These data indicate that the P-Jun+/SMI-32MNs in Bax-KO mice may represent the developmentally rescued subpopulation of atrophic MNs described previously that would have undergone PCD in the presence of the Bax gene (Sun et al., 2003). By P10, P-Jun + cells were no longer observed in the ventral horn of either WT or Bax-KO mice (data not shown).
Previously, we observed that a subset of atrophied (SMI-32-negative) facial MNs could be visualized by retrograde labeling from the whisker pad at P1 (Sun et al., 2003). The normal period of cell death for facial MNs in the mouse is between E17 and P5-P6 (Ashwell and Watson, 1983; Sun et al., 2003). Because we found that these retrogradely labeled, atrophied MNs are fated to later progressively lose their target contacts, we examined P-Jun IR after retrograde tracing to assess the relationship of target contacts and c-Jun phosphorylation (Fig. 6D-F). After a $2 \mathrm{~d}$ survival after tracer injection at P1, 30\% of retrogradely labeled facial MNs were $\mathrm{P}-J u n+$ in Bax-KO mice, whereas $<9 \%$ labeled MNs were P-Jun + in WT mice (Fig. 6E). In the Bax-KO, many retrogradely labeled cells exhibited small soma size and an eccentrically positioned nucleus (atrophic MNs), and we have separately quantified the percentage of P-Jun + cells in these two distinct (normal-sized vs atrophied) populations (Fig. $6 F$ ). Whereas there were $<10 \%$ P-Jun + cells among retrogradely labeled normal $\mathrm{MNs}, \sim 70 \%$ of the atrophic MNs were P-Jun +. Furthermore, we observed that $\sim 15 \%$ of the $\mathrm{P}$-Jun + cells were not retrogradely labeled, suggesting that c-Jun phosphorylation is related to the loss of target contacts. Together, we conclude from these data that the increased number of P-Jun + cells in the developing Bax-KO is most likely a result of the progressive reduction of target-derived trophic signals.

\section{Reduced PCD of MNs by blockade of c-Jun signaling in the chick embryo}

To assess the physiological importance of c-Jun phosphorylation in developing MNs, we next asked whether c-Jun signaling blockade influence the viability of developing MNs. The deletion of the $\mathrm{C}$ terminus of c-Jun has been used for the inhibition of c-Jun signaling in a dominant-negative manner (Whitfield et al., 2001). Therefore, we first examined whether overexpression of DN-Jun in developing chick spinal cord suppresses PCD (Fig. 7). After the electroporation of plasmids encoding YFP-tagged DN-Jun into the lumbar spinal cord at E3 (HH st. 16), typically $10-40 \%$ of ipsilateral MNs exhibited YFP fluorescence at E7, and only sections containing $>25 \%$ MNs with the YFP signal were included for additional analyses. Whereas control electroporation of a blank YFP vector did not modify the viability of MNs, there was a significant reduction of activated caspase-3 IR and pyknotic cells on the DN-Jun-electroporated side, suggesting that perturbation of c-Jun signaling by DN-Jun expression greatly suppressed downstream caspase activation (Fig. 7D). Overexpression of neither DN-Jun nor control YFP modified the percentage of P-Jun+ cells, indicating that DN-Jun expression perturbed c-Jun signaling downstream of c-Jun phosphorylation (data not shown). On the other hand, the ratio of Islet $1 / 2+$ cells on the ipsilateral versus contralateral side was not significantly increased by DN-Jun or YFP control overexpression at E7. We reasoned that this is partially because of the reduction of $\mathrm{MN}$ production (proliferation) 
(Hollyday and Hamburger, 1977) after DN-Jun overexpression, because there was significantly fewer MNs in the DN-Junexpressing half of the spinal cord at E5, which is before the onset of PCD (Fig. 7C). Consistent with this possibility, it has been reported that fibroblasts from mice with a knock-in mutation of the phosphorylation site of c-Jun exhibit an impairment of proliferation as well as apoptosis (Behrens et al., 1999). Although additional studies are required to examine the role of c-Jun signaling in the generation of MNs, our data suggest that c-Jun signaling may also be involved in the neurogenesis of MNs.

Next, we assessed the number of dying MNs in the chick embryo $16 \mathrm{~h}$ after treatment with a selective Jun kinase inhibitor ex vivo (Fig. 8). We used a selective Jun kinase inhibitor, D-JIKI1, which significantly suppressed the phosphorylation of c-Jun in cultured MNs after trophic factor deprivation (Fig. $8 A$ ). E7.5 chick embryo trunk/spinal cord-hindlimb preparations were injected with D-JIKI1 or saline and maintained for $16 \mathrm{~h}$ ex vivo. The number of dying MNs in the lumbar spinal cord in D-JIKI1-injected embryos was significantly reduced compared with salineinjected controls $(p<0.001$; Student's $t$ test; $n=7$, both groups). The number of pyknotic motoneurons in saline control embryos was similar to the number previously observed in vivo at E7.5 (Llado et al. 1999). Collectively, these results indicate that the activation of JNK and phosphorylation of c-Jun is necessary for the PCD of MNs in vivo.

\section{Discussion}

Developmental PCD of MNs in vivo is not a synchronized process, and markers available for the investigation of PCD are virtually all related to end-stage events of the cell-death cascade (e.g., pyknotic nucleus, nuclear condensation, DNA degradation, caspase- 3 activation, etc.). Therefore, because it has been difficult to examine early events during the PCD of MNs, the present results are of particular interest in showing that c-Jun phosphorylation may be a good marker for assessing an early stage of PCD of MNs in vivo, when these cells express few, if any, other markers of their subsequent fate.

Phosphorylation of c-Jun is an early and reversible step of the PCD activation in vivo

Phosphorylation of c-Jun has been identified previously as one of the earliest biochemical changes signaling neuronal death after NGF deprivation in cultured sympathetic neurons (Easton et al., 1997; Deckwerth et al., 1998). Because the survival of MNs in vivo is dependent on neurotrophic factors, we assume that c-Jun phosphorylation takes place in the subset of MNs in which the PCD cascade is activated after failure to obtain sufficient trophic support. The fact that c-Jun phosphorylation was only observed

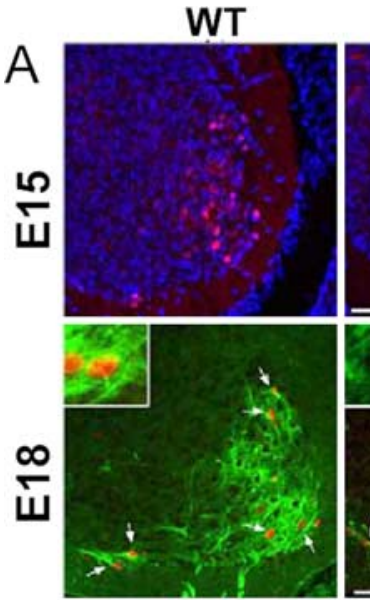

\section{Bax-KO}
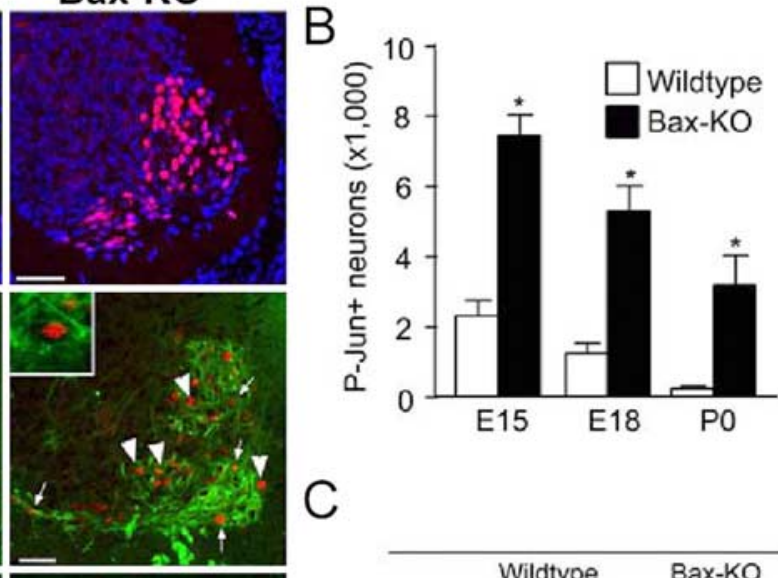

\begin{tabular}{lcc}
\hline & Wildtype & Bax-KO \\
\hline P-Junt & $293 \pm 40$ & $3380 \pm 269^{*}$ \\
$\begin{array}{l}\text { P-Jun+ } \\
\text { ISMI32+ }\end{array}$ & $253 \pm 42$ & $290 \pm 75$ \\
$\begin{array}{l}\text { P-Jun+ } \\
\text { ISMI32- }\end{array}$ & $40 \pm 17$ & $3090 \pm 269^{*}$ \\
\hline & & ${ }^{*} p<0.05$
\end{tabular}

$\mathrm{F}$
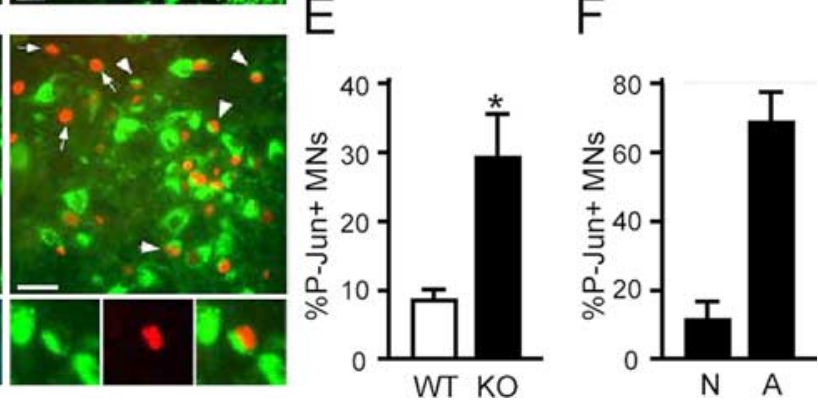

Figure 6. A, Phosphorylation of c-Jun in developing (E15, E18, and P0) WT and Bax-K0 mice. Colabeling for phosphorylated c-Jun (red) and an MN marker (SMI-32; green) is shown. Because E15 MNs do not yet express SMI-32 IR, nuclear-counterstained 33342; blue) images are shown in $\boldsymbol{A}$. Arrows (E18, PO) indicate P-Jun +/SMI-32+ MNs, and arrowheads indicate ( exhibited P-Jun IR (arrowheads and bottom panels). There were also many unlabeled P-Jun + cells (arrows). Scale bar, $60 \mu \mathrm{m} . \boldsymbol{E}$, each of $n=3$ animals. * $p<0.05$; Student's $t$ test. $F$, Quantification of P-Jun + cells between normal (N) and atrophied (A) MNs in Bax-K0 mice. Three different sections and $>200$ cells were examined in each of $n=3$ animals.

in a subpopulation of spinal MNs during the normal PCD period in both chicks and mice is consistent with this argument. Although not examined here in detail, this was also the case in other neuronal populations in vivo that exhibit trophic factordependent cell death, including DRG and SCG neurons. In contrast, chick spinal interneurons, which do not undergo developmental PCD (McKay and Oppenheim, 1991), never exhibited c-Jun phosphorylation. This is the first in vivo evidence consistent with the idea that c-Jun phosphorylation occurs in neurons that fail to obtain sufficient trophic factor support. Additional evidence from experimental alteration of the availability of targetderived trophic signals is also consistent with this idea. For example, the removal of a potent source of trophic signals by early limb bud removal greatly augments the number of cells that exhibit c-Jun phosphorylation and increases the PCD of MNs, whereas putative increases in trophic signals after activity blockade re- 
A

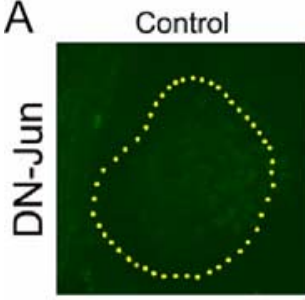

Electroporated $\mathrm{B}$
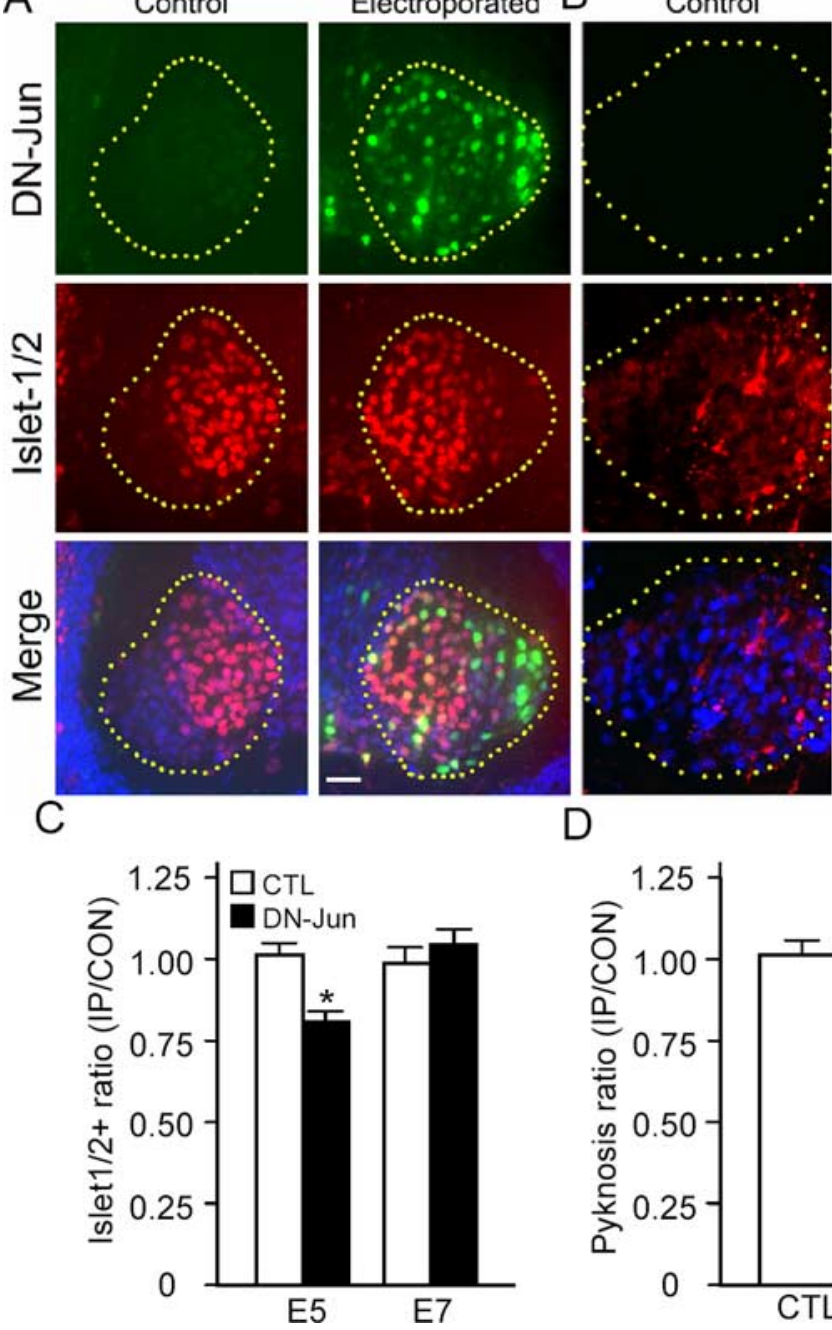

Electroporated
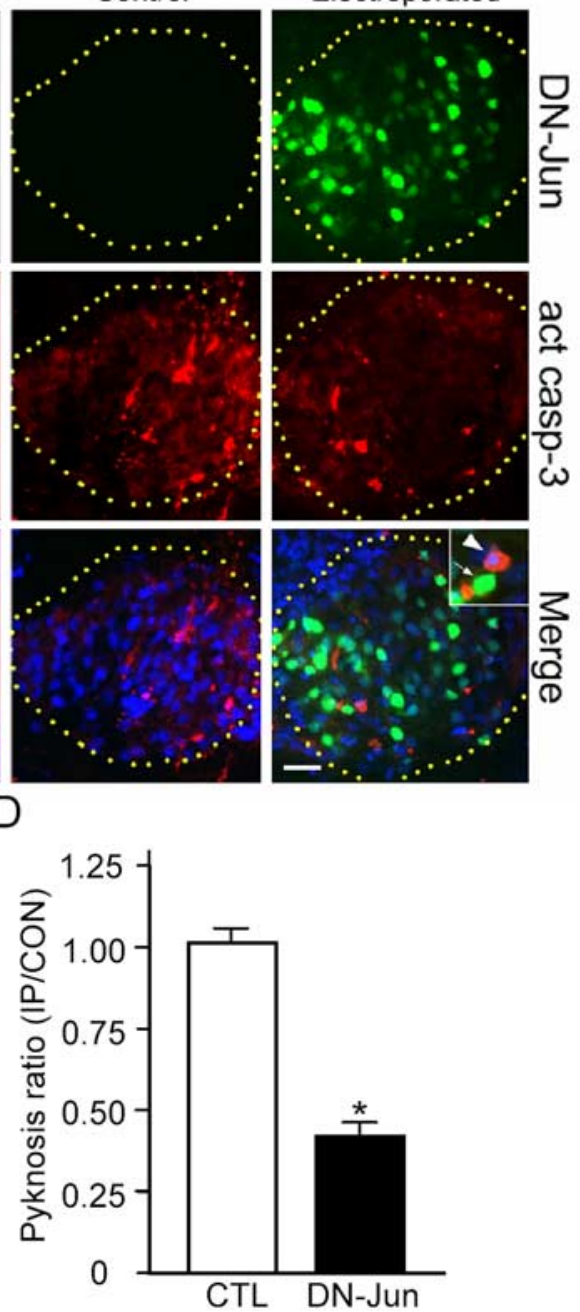

Figure 7. Overexpression of DN-Jun reduced the PCD of MNs. $\boldsymbol{A}, \boldsymbol{B}$, Comparison of Islet $1 / 2+(\boldsymbol{A})$ or activated caspase- $3+$ (act casp-3; $\boldsymbol{B}$ ) cells after DN-Jun electroporation on control (contralateral) and electroporated (ipsilateral) sides of spinal cord on E7. Note that most DN-Jun + cells lack caspase-3 IR ( $\boldsymbol{B}$, insets; the arrow indicates a DN-Jun + cell, and the arrowhead indicates a caspase-3+ cell). Scale bar, $60 \mu \mathrm{m}$. $\boldsymbol{C}, \boldsymbol{D}$, Quantification of the Islet $1 / 2+(\boldsymbol{A})$ or activated caspase-3+ (B) cells. Because slightly different levels of the spinal cord were optimally electroporated in each embryo, the ratio of ipsilateral (IP) to contralateral (CON) was examined from the same plane of section. At least three to five regularly spaced sections were examined, and the mean value was used for each of $n=5$ animals' scores. ${ }^{*} p<0.05$; Student's $t$ test. CTL, Control. Error bars represent SD.

duces the numbers of cells expressing c-Jun phosphorylation and increases MN survival.

In contrast to the situation during activity blockade, however, in the period after the transient (E5-E9) blockade of neuromuscular activity, there is a striking increase in the number of P-Jun+ MNs that correlates with the delayed loss of rescued MNs that begins $3 \mathrm{~d}$ (E12) after the termination of activity blockade. Although not examined here, we assume that the increased intramuscular axon branching that occurs during activity blockade (Dahm and Landmesser, 1988) is not maintained during the period after E12, which according to the access hypothesis (Oppenheim, 1989) would reduce access to target-derived trophic support. Therefore, we speculate that in this situation, there is a reduction in available target-derived trophic signals in the face of an excess number of surviving MNs, resulting in a large increase $(>70 \%)$ in the number of MNs that express the early PCD signal, phosphorylated c-Jun. The same argument may be applicable to the increased number of P-Jun + MNs in the Bax-KO embryos. Although Bax-KO MNs never undergo developmental PCD
(Deckwerth et al., 1996; White et al., 1998), postnatally, a subpopulation of Bax-KO-rescued MNs lose target innervation and atrophy even in the face of a normal expression of MN trophic factors in muscle (Sun et al., 2003). On E15, there are excess MNs in the Bax-KO mice that have initiated target innervation (Sun et al., 2003), and their presence may result in increased competition for limiting amounts of target-derived signals that results in c-Jun phosphorylation by a majority of MNs as an early index of trophic signal deprivation (increased competition).

Postnatally, when the Bax-KO-rescued subpopulation of MNs lose target innervation and atrophy, there is a significant reduction in the number of P-Jun + neurons compared with E15. Interestingly, although a majority of the P-Jun + MNs in the Bax-KO did not exhibit SMI-32 IR, SMI-32+/P-Jun+ MN numbers were similar in WT and Bax-KO mice (Fig. 5C). We observed previously that the excess $\mathrm{MNs}$ in neonatal Bax-KO mice become atrophic and lose SMI-32 IR (Sun et al., 2003). Because most Bax-KO MNs are P-Jun + at earlier developmental stages (E15), these data indicate that SMI-32positive MNs specifically lose P-Jun IR, whereas the SMI-32-negative, atrophic MNs retain P-Jun IR as they become denervated and are thus excluded from competition for target-derived trophic support. Visualization of atrophied MNs by retrograde labeling clearly demonstrated that the majority of atrophied, SMI-32negatvive MNs exhibited P-Jun IR. This suggests that in the Bax-KO mice, a subset of MNs are able to obtain sufficient trophic support and become SMI-32+/PJun-, at the same time that other MNs are being excluded from the competitive pool (SMI-32-/P-Jun +) by their failure to sustain target innervation. In cultured sympathetic neurons, the phosphorylation of c-Jun is also a reversible step in that P-Jun+ neurons can be rescued from apoptosis if NGF is provided before Bax becomes translocated to the mitochondrial membrane (Deckwerth et al., 1998; Putcha et al., 1999). We find that by P10, $\mathrm{P}-\mathrm{Jun}+\mathrm{MNs}$ are no longer observed in either WT or Bax-KO mice, suggesting that c-Jun has now become dephosphorylated in the subset of surviving but atrophic MNs in the Bax-KO.

Because some nondegenerating MNs also become P-Jun + in both WT mice and normal chick embryos during the PCD period, these may represent MNs that will later exit from the PCD cascade and go on to survive, consistent with the situation described above in Bax-KO mice. For instance, $\sim 20 \%$ of MNs degenerate within a $24 \mathrm{~h}$ period during the peak time of PCD on E7.5-E8 in the normal chick embryo (Calderó et al., 1998), whereas we observed that $\sim 30 \%$ of MNs were P-Jun + at E8 and that there is a substantial number $(\sim 10 \%)$ of P-Jun + MNs still present on E12-E14, which is after the PCD period ends on E11. Accordingly, despite no further loss of MNs between E12 and 

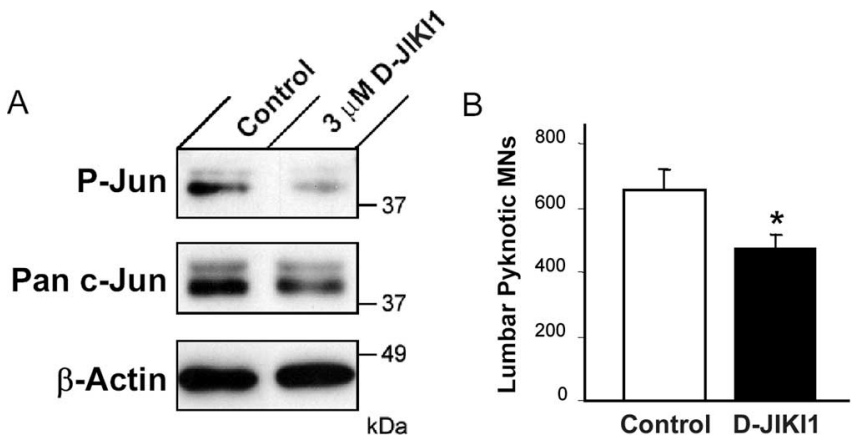

Figure 8. Hindlimb muscle injection with a Jun kinase inhibitor reduces MN death ex vivo. $\boldsymbol{A}$, D-JIKI1, a selective inhibitor of Jun kinase, reduced the phosphorylation of c-Jun in E5 chick lumbar MNs cultured for $8 \mathrm{~h}$, as described in Materials and Methods (Milligan et al., 1994). The total amount of c-Jun protein (Pan c-Jun) was moderately reduced, which appears to be attributable to the inhibition of transcriptional autoregulation (Angel et al., 1988). B, Quantification of pyknotic MNs in lumbar spinal cord after ex vivo treatment with D-JIKI1. The number of dying MNs in the lumbar spinal cord in D-JIKI1-injected embryos is significantly less than in the lumbar spinal cord of saline-injected controls ( ${ }^{*} p<0.001$; Student's $t$ test; $n=7$, both groups). Error bars represent SD.

E14, these P-Jun + neurons lose P-Jun immunoreactivity by E16, indicating that they do not proceed further in the PCD cascade and thus downregulate the phosphorylation of c-Jun. Therefore, a subset of P-Jun $+\mathrm{MNs}$ in vivo appear to be rescued from normal PCD because they can eventually obtain sufficient trophic support, because of the elimination of other MNs by cell death from the competitive pool. Supporting this idea, we observed that $\sim 50 \%$ of P-Jun + MNs exhibited P-Akt IR. Because PI3K-Akt signaling is one of the major pathway for the neurotrophic factor survival signaling in neurons, this result suggests that a subpopulation of P-Jun + MNs maintain or regain the activation of neurotrophic factor signaling. Although it is unclear whether these two major signaling pathways are sufficient to restrict the fate of MNs destined to die, our observation suggests that there may be significant heterogeneity of c-Jun and Akt phosphorylation in MNs during the period of competition for trophic support and that interactions of these signaling cascades may contribute to the selection process of $\mathrm{MN}$ fate. This may occur in both normal development and the delayed PCD (activity-blockade) model in the chick, as well as in the Bax-KO as subsets of rescued MNs lose target innervation and no longer compete for target-derived trophic signals. This model of competition for trophic factor survival signals by developing MNs is consistent with the neurotrophic hypothesis (see supplemental material, available at www.jneurosci.org).

\section{c-Jun phosphorylation is required for the early activation of PCD cascade in vivo}

To assess whether c-Jun phosphorylation is required for $\mathrm{MN}$ PCD, we examined the viability of MNs after perturbation of c-Jun signaling in vivo. To accomplish this, we used two different in vivo methods, the overexpression of DN-Jun to block the downstream events of c-Jun phosphorylation and the inhibition of JNK to block phosphorylation of c-Jun. Because blockade of JNK-Jun signaling both before and after the c-Jun phosphorylation step significantly attenuated the PCD of MNs, we conclude that c-Jun phosphorylation is necessary for the PCD of MNs. There are several reports demonstrating that inhibition of JNKJun signaling may inhibit neuronal death in vivo. For instance, overexpression of DN-Jun significantly repressed axotomyinduced dopaminergic neuronal death (Crocker et al., 2001), and an inhibitor of upstream kinase of JNKs, CEP1347, effectively rescued MNs from PCD in vivo and in vitro (Glicksman et al., 1998; Maroney et al., 1998). Consistent with our observations, Raivich et al. (2004) demonstrated that nervous system-specific knock-out of c-Jun in mice increased the number of surviving facial MNs (Raivich et al., 2004). Activation of JNK-c-Jun signaling appears to induce the translocation of Bax, via transcriptional activation of $\mathrm{BH} 3$ only proteins (Bim) or via direct interaction of Bim and JNK (Harris and Johnson, 2001; Okuno et al., 2004).

Although it is clear that the induction of c-Jun is required for neuronal death, there is also a large body of evidence suggesting that c-Jun signaling is involved in the regeneration of MNs. For instance, the expression of c-Jun was increased during $\mathrm{MN}$ regeneration after axotomy (Leah et al., 1991), and the neuron-specific c-Jun knock-out mice fail to execute an axonal regenerative response (Raivich et al., 2004). Therefore, it seems likely that c-Jun signaling is sensitive to cellular stresses such as an insufficient supply of trophic signals and may be able to trigger both celldeath pathways and axonal regenerative processes depending on the cellular and developmental context.

\section{References}

Angel P, Hattori K, Smeal T, Karin M (1988) The jun proto-oncogene is positively autoregulated by its product, Jun/AP-1. Cell 55:875-885.

Ashwell KW, Watson CR (1983) The development of facial motoneurons in the mouse: neuronal death and the innervation of facial muscles. J Embryol Exp Morph 77:117-141.

Ayala V, Casas C, Ribera J, Calderó J, Oppenhiem RW, Esquerda JE (1999) Specific association of c-Jun-like immunoreactivity but not c-Jun p39 with normal and induced programmed cell death in the chick embryo. J Neurobiol 38:171-190.

Behrens A, Sibilia M, Wagner EF (1999) Amino-terminal phosphorylation of c-Jun regulates stress-induced apoptosis and cellular proliferation. Nat Genet 21:326-329.

Bonny C, Oberson A, Negri S, Sauser C, Schorderet DF (2001) Cell permeable peptide inhibitors of JNK novel blockers of $\beta$-cell death. Diabetes 50:77-82.

Borsello T, Croquelois K, Hornung JP, Clarke PG (2003a) N-methyl-Daspartate-triggered neuronal death in organotypic hippocampal cultures is endocytic, autophagic and mediated by the c-Jun N-terminal kinase pathway. Eur J Neurosci 18:473-485.

Borsello T, Clarke PG, Hirt L, Vercelli A, Repici M, Schorderet DF, Bogousslavsky J, Bonny C (2003b) A peptide inhibitor of c-Jun N-terminal kinase protects against excitotoxicity and cerebral ischemia. Nat Med 9:1180-1186.

Brunet A, Datta SR, Greenberg ME (2001) Transcription-dependent and -independent control of neuronal survival by the PI3K-Akt signaling pathway. Curr Opin Neurobiol 11:297-305.

Calderó J, Prevette D, Mei X, Oakley RA, Li L, Milligan C, Houenou L, Burek M, Oppenheim RW (1998) Peripheral target regulation of the development and survival of spinal sensory and motor neurons in the chick embryo. J Neurosci 18:356-370.

Cascas C, Ribera J, Esquerda JE (2001) Antibodies against c-Jun N-terminal peptide cross-react with neo-epitopes emerging after caspase-mediated proteolysis during apoptosis. J Neurochem 77:904-915.

Chun LL, Patterson PH (1977) Role of nerve growth factor in the development of rat sympathetic neurons in vitro. I. Survival, growth, and differentiation of catecholamine production. J Cell Biol 75:694-704.

Crocker SJ, Lamba WR, Smith PD, Callaghan SM, Slack RS, Anisman H, Park DS (2001) c-Jun mediates axotomy-induced dopamine neuron death in vivo. Proc Natl Acad Sci USA 98:13385-13390.

Dahm L, Landmesser L (1988) The regulation of intramuscular nerve branching during normal development and following activity blockade. Dev Biol 130:621-644.

Deckwerth TL, Elliott JL, Knudson CM, Johnson Jr EM, Snider WD, Korsmeyer SJ (1996) BAX is required for neuronal death after trophic factor deprivation and during development. Neuron 17:401-411.

Deckwerth TL, Easton RM, Knudson CM, Korsmeyer SJ, Johnson Jr EM (1998) Placement of the BCL2 family member BAX in the death pathway 
of sympathetic neurons activated by trophic factor deprivation. Exp Neurol 152:150-162.

Easton RM, Deckwerth TL, Parsadanian AS, Johnson Jr EM (1997) Analysis of the mechanism of loss of trophic factor dependence associated with neuronal maturation: a phenotype indistinguishable from Bax deletion. J Neurosci 17:9656-9666.

Glicksman MA, Chiu AY, Dionne CA, Harty M, Kaneko M, Murakata C, Oppenheim RW, Prevette D, Sengelaub DR, Vaught JL, Neff NT (1998) CEP-1347/KT7515 prevents motor neuronal programmed cell death and injury-induced dedifferentiation in vivo. J Neurobiol 35:361-370.

Gould TW, Oppenheim RW (2004) The function of neurotrophic factor receptors expressed by the developing adductor motor pool in vivo. J Neurosci 24:4668-4682.

Greene LA (1977) Quantitative in vitro studies on the nerve growth factor (NGF) requirement of neurons. I. Sympathetic neurons. Dev Biol 58:96-105.

Grieshammer U, Lewandoski M, Prevette D, Oppenheim RW, Martin GR (1998) Muscle-specific cell ablation conditional upon Cre-mediated DNA recombination in transgenic mice leads to massive spinal and cranial motoneuron loss. Dev Biol 197:234-247.

Hamburger V (1975) Cell death in the development of the lateral motor column of the chick embryo. J Comp Neurol 160:535-546.

Hamburger V, Hamilton HL (1951) A series of normal stages in the development of the chick embryo. J Morphol 88:49-92.

Hamburger V, Levi-Montalcini R (1949) Proliferation, differentiation and degeneration in the spinal ganglia of the chick embryo under normal and experimental conditions. J Exp Zool 111:457-501.

Harris CA, Johnson Jr EM (2001) BH3-only Bcl-2 family members are coordinately regulated by the JNK pathway and require Bax to induce apoptosis in neurons. J Biol Chem 276:37754-37760.

Herzog KH, Chen SC, Morgan JI (1999) c-jun is dispensable for developmental cell death and axogenesis in the retina. J Neurosci 19:4349-4359.

Hollyday M, Hamburger V (1977) An autoradiographic study of the formation of the lateral motor column in the chick embryo. Brain Res 132:197-208.

Kaplan DR, Miller FD (2000) Neurotrophin signal transduction in the nervous system. Curr Opin Neurobiol 10:381-391.

Knudson CM, Tung KS, Tourtellotte WG, Brown GA, Korsmeyer SJ (1995) Bax-deficient mice with lymphoid hyperplasia and male germ cell death. Science 270:96-99.

Landmesser L (1992) The relationship of intramuscular nerve branching and synaptogenesis to motoneuron survival. J Neurobiol 23:1131-1139.

Leah JD, Herdegen T, Bravo R (1991) Selective expression of Jun proteins following axotomy and axonal transport block in peripheral nerves in the rat: evidence for a role in the regeneration process. Brain Res 566:198-207.

Llado J, Caldero J, Ribera J, Tarabal O, Oppenheim RW, Esquerda JE (1999) Opposing effects of excitatory amino acids on chick embryo spinal cord motoneurons: excitotoxic degeneration or prevention of programmed cell death. J Neurosci 19:10803-10812.

Maroney AC, Glicksman MA, Basma AN, Walton KM, Knight Jr E, Murphy CA, Bartlett BA, Finn JP, Angeles T, Matsuda Y, Neff NT, Dionne CA (1998) Motoneuron apoptosis is blocked by CEP-1347 (KT 7515), a novel inhibitor of the JNK signaling pathway. J Neurosci 18:104-111.

McKay SE, Oppenheim RW (1991) Lack of evidence for cell death among avian spinal cord interneurons during normal development and following removal of targets and afferents. J Neurobiol 22:721-733.

Miller T, Moulder KL, Knudson CM, Creedon DJ, Deshmukh M, Korsmemer SJ, Johnson Jr EM (1997) Bax deletion further orders the cell death pathway in cerebellar granule cells and suggests a caspase-independent pathway to cell death. J Cell Biol 139:205-217.

Milligan CE, Oppenheim RW, Schwartz LM (1994) Motoneurons deprived of trophic support in vitro require new gene expression to undergo programmed cell death. J Neurobiol 25:1005-1016.

Okuno S, Saito A, Hayashi T, Chan PH (2004) The c-Jun-N-terminal kinase signaling pathway mediates Bax activation and subsequent neuronal apoptosis through interaction with Bim after transient focal cerebral ischemia. J Neurosci 24:7879-7887.

Oppenheim RW (1989) The neurotrophic theory and naturally occurring motoneuron death. Trends Neurosci 12:252-255.

Oppenheim RW (1991) Cell death during development of the nervous system. Annu Rev Neurosci 14:453-501.

Oppenheim RW, Prevette D, D'Costa A, Wang S, Houenou LJ, McIntosh JM (2000) Reduction of neuromuscular activity is required for the rescue of motoneurons from naturally occurring cell death by nicotinic-blocking agents. J Neurosci 20:6117-6124.

Phelan KA, Hollyday M (1991) Embryonic development and survival of brachial motoneurons projecting to muscleless chick wings. J Comp Neurol 311:313-320.

Pittman R, Oppenheim RW (1979) Cell death of motoneurons in the chick embryo spinal cord. IV. Evidence that a functional neuromuscular interaction is involved in the regulation of naturally occurring cell death and the stabilization of synapses. J Comp Neurol 187:425-446.

Pittman R, Oppenheim RW, Chu-Wang IW (1978) B-bungarotoxin induced neuronal degeneration in the chick embryo spinal cord. Brain Res 153:199-204.

Putcha GV, Deshmukh M, Johnson Jr EM (1999) BAX translocation is a critical event in neuronal apoptosis: regulation by neuroprotectants, BCL-2, and caspases. J Neurosci 19:7476-7485.

Putcha GV, Moulder KL, Golden JP, Bouillet P, Adams JA, Strasser A, Johnson Jr EM (2001) Induction of BIM, a proapoptotic BH3-only Bcl-2 family member, is critical for neuronal apoptosis. Neuron 29:615-628.

Raivich G, Bohsschek M, Costa CD, Iwata O, Galiano M, Hristova M, RieraSans L, Wolfer DP, Lipp H-P, Aguzzi A, Wagner EF, Behrens A (2004) The AP- 1 transcription factor c-Jun is required for efficient axonal regeneration. Neuron 43:57-67.

Sato N, Sakuma C, Kato H, Milligan CE, Oppenheim RW, Yaginuma H (2002) Bcl-2 rescues motoneurons from early cell death in the cervical spinal cord of the chick embryo. J Neurobiol 53:381-390.

Sun W, Oppenheim RW (2003) Response of motoneurons to neonatal sciatic nerve axotomy in Bax-knockout mice. Mol Cell Neurosci 24:875-886.

Sun W, Gould TW, Vinsant S, Prevette D, Oppenheim RW (2003) Neuromuscular development after the prevention of naturally occurring neuronal death by Bax deletion. J Neurosci 23:7298-7310.

White FA, Keller-Peck CR, Knudson CM, Korsmeyer SJ, Snider WD (1998) Widespread elimination of naturally occurring neuronal death in Baxdeficient mice. J Neurosci 18:1428-1439.

Whitfield J, Neame SJ, Paquet L, Bernard O, Ham J (2001) Dominantnegative c-Jun promotes neuronal survival by reducing BIM expression and inhibiting mitochondrial cytochrome c release. Neuron 29:629-643. 